\title{
Modelagem de propriedades geológico-geotécnicas em solos de Belém do Pará
}

\author{
Modeling of geological-geotechnical properties in soils of Belém do Pará \\ Modelado de propiedades geológico-geotécnicas en suelos de Belém do Pará
}

Recebido: 04/02/2021 | Revisado: 07/02/2021 | Aceito: 13/02/2021 | Publicado: 21/02/2021

\author{
Marina Nascimento Alves Vieira \\ ORCID: https://orcid.org/0000-0003-1908-6767 \\ Centro Universitário Metropolitano da Amazônia, Brasil \\ E-mail: marinaalvesv@gmail.com \\ Camila Nascimento Alves \\ ORCID: https://orcid.org/0000-0001-5093-7078 \\ Universidade do Estado do Pará, Brasil \\ E-mail: camilanascimentoalves@gmail.com \\ Vyviane dos Santos Ferreira \\ ORCID: https://orcid.org/0000-0001-9798-4234 \\ Centro Universitário Metropolitano da Amazônia, Brasil \\ E-mail: vyvianesf@gmail.com \\ Cleisianne Nazaré Leite Barbosa \\ ORCID: https://orcid.org/0000-0002-0052-1864 \\ Centro Universitário Metropolitano da Amazônia, Brasil \\ E-mail: cleisi.barbosa@gmail.com
}

\begin{abstract}
Resumo
O objetivo da pesquisa apresentada neste artigo foi realizar a modelagem de propriedades geológico-geotécnicas no subsolo de um bairro no município de Belém do Pará a partir de sondagem à percussão, usando como ferramenta a geoestatística. Para alcançar o objetivo realizou-se a catalogação do acervo técnico contendo 101 boletins de sondagem à percussão. Criou-se um banco de dados contendo os dados de coordenadas geográficas, tipo de solo, profundidade das camadas do solo, nível do lençol freático e Índice de Resistência à Penetração (NSPT), conforme a norma NBR 6484/2001. Os dados foram analisados em ambiente SIG (Sistema de Informação Geográfica) com softwares Open Source, como SGEMS (Standford Geoestatistical Modeling Software) para análise geoestatística e o software Qgis para análises cartográficas. Distinguiu-se duas zonas díspares na região de estudo, denominadas de Zona A e Zona B. A Zona A é considerada uma região com os maiores índices de resistência dos solos e a Zona B uma região com menores índices de resistência, conforme demonstrado nos mapas. Na região ocorrem argilas orgânicas de baixa resistência nas proximidades das áreas de várzea, onde no passado eram localizados os igarapés. No entanto, esses locais foram retificados durante o processo de urbanização. E, atualmente, localizam-se as regiões de baixa resistência descritas nos resultados desta pesquisa.
\end{abstract}

Palavras-chave: Geoestatística; Geotecnia; Planejamento urbano; Belém do Pará.

\begin{abstract}
The objective of the research presented in this article was to perform the modeling of geological and geotechnical properties in the subsoil of a neighborhood in the city of Belém do Pará, using percussion drilling, using geostatistics as a tool. To achieve the objective, the cataloging of the technical collection was carried out, containing 101 percussion survey bulletins. A data base was created containing data on geographic coordinates, soil type, depth of soil layers, ground water level and Penetration Resistance Index (NSPT), according to NBR 6484/2001. The data were analyzed in a GIS environment (Geographic Information System) with Open Source software such as SGEMS (Standford Geostatistical Modeling Software) for geostatistical analysis and the Qgis software for cartographic analysis. Two disparate zones were distinguished in the study region, called Zone A and Zone B. Zone A is considered to be a region with the highest soil resistance indexes and Zone B is a region with the lowest resistance indexes, as shown in the maps . In the region there are organic clays of low resistance in the vicinity of the floodplain areas, where the streams were located in the past. However, these locations were rectified during the Urbanization process. And currently, the regions of low resistance described in the results of this research are located.
\end{abstract}

Keywords: Geostatistics; Geotechnics; Urban planning; Belém do Pará.

\section{Resumen}

El objetivo de la investigación que se presenta en este artículo fue realizar el modelado de propiedades geológicas y geotécnicas en el subsuelo de un barrio de la ciudad de Belém do Pará, utilizando perforación de percusión, utilizando como herramienta la geoestadística. Para lograr el objetivo, se realizó la catalogación de la colección técnica, que contiene 101 boletines de encuestas de percusión. Se creó una base de datos que contiene datos sobre coordenadas 
geográficas, tipo de suelo, profundidad de las capas del suelo, nivel del agua subterránea e Índice de Resistencia a la Penetración (NSPT), según NBR 6484/2001. Los datos se analizaron en un entorno GIS (Geographic Information System) con software de código abierto, como SGEMS (Standford Geostatistical Modeling Software) para análisis geoestadístico y el software Qgis para análisis cartográfico. Se distinguieron dos zonas dispares en la región de estudio, denominadas Zona A y Zona B. La Zona A se considera la región con los índices de resistencia del suelo más altos y la Zona B es una región con los índices de resistencia más bajos, como se muestra en los mapas. En la región existen arcillas orgánicas de baja resistencia en las cercanías de las zonas de llanura aluvial, donde en el pasado se ubicaban los arroyos. Sin embargo, estas ubicaciones fueron rectificadas durante el proceso de urbanización. Y en la actualidad se localizan las regiones de baja resistencia descritas en los resultados de esta investigación.

Palabras clave: Geoestadística; Geotecnia; Planificación urbana; Belém do Pará

\section{Introduçãa}

Belém é a capital do Estado do Pará, cuja localização se dá na confluência do Rio Guamá com a Baía do Guajará (Vieira \& Cruz, 2019). Sua expansão territorial se deu por três fases, denominadas por Moreira (1966) como Ribeirinha, Penetração e Contemporânea. Penteado (1968) descreve que inicialmente a ocupação se deu pelas margens fluviais e futuramente pela penetração da mata. O autor ainda esclarece que, conforme o progresso era incentivado internacionalmente a partir da popularização da indústria de borracha, as regiões centrais eram supervalorizadas e tornadas comerciais. Esse processo forçava as famílias com menor poder aquisitivo, ou seja, mais pobres se locomoverem para a proximidade de várzeas distantes do centro.

Bezerra (2019) afirma que existia uma aversão às regiões de várzea por serem propensas a alagamentos e inundações, fato que incentivou a ocupação em cotas altimétricas mais altas e distantes de igarapés. Penteado (1968) descreve uma evidente tendência de expansão urbana dada a abertura de uma importante via no subúrbio do Marco da Légua, contemporaneamente conhecida como Almirante Barroso. Nos limites desse subúrbio, hoje conhecido como Bairro do Marco, há a nascente do Igarapé do Tucunduba. Matos (2010) destaca que, a partir de 1970, ocupações clandestinas surgiram ao longo do Tucunduba, mudando suas características naturais. A pesquisa de Targa (2012) complementa Matos (2010), no que tange ao aterramento das áreas alagadiças.

"No processo de ocupação do Tucunduba, logo após o desmatamento da área, ocorreu a colocação das estivas de madeira para a construção de palafitas. Uma vez instalada, a população utilizou laterita ou piçarra, lixo e outros detritos, como caroços de açaí e serragem para constituir aterro para acesso às palafitas.” (Targa, 2012, p. 129)

Dadas alterações substanciais na bacia do Tucunduba, foram necessárias obras de macrodrenagem para resolução dos problemas de drenagem. Entretanto, tais obras ainda não foram suficientes para sanar as carências e discrepâncias dentro de um bairro extenso. A Figura 1 apresenta uma subseção do bairro 
Figura: Localização e cota altimétrica da área de estudo.
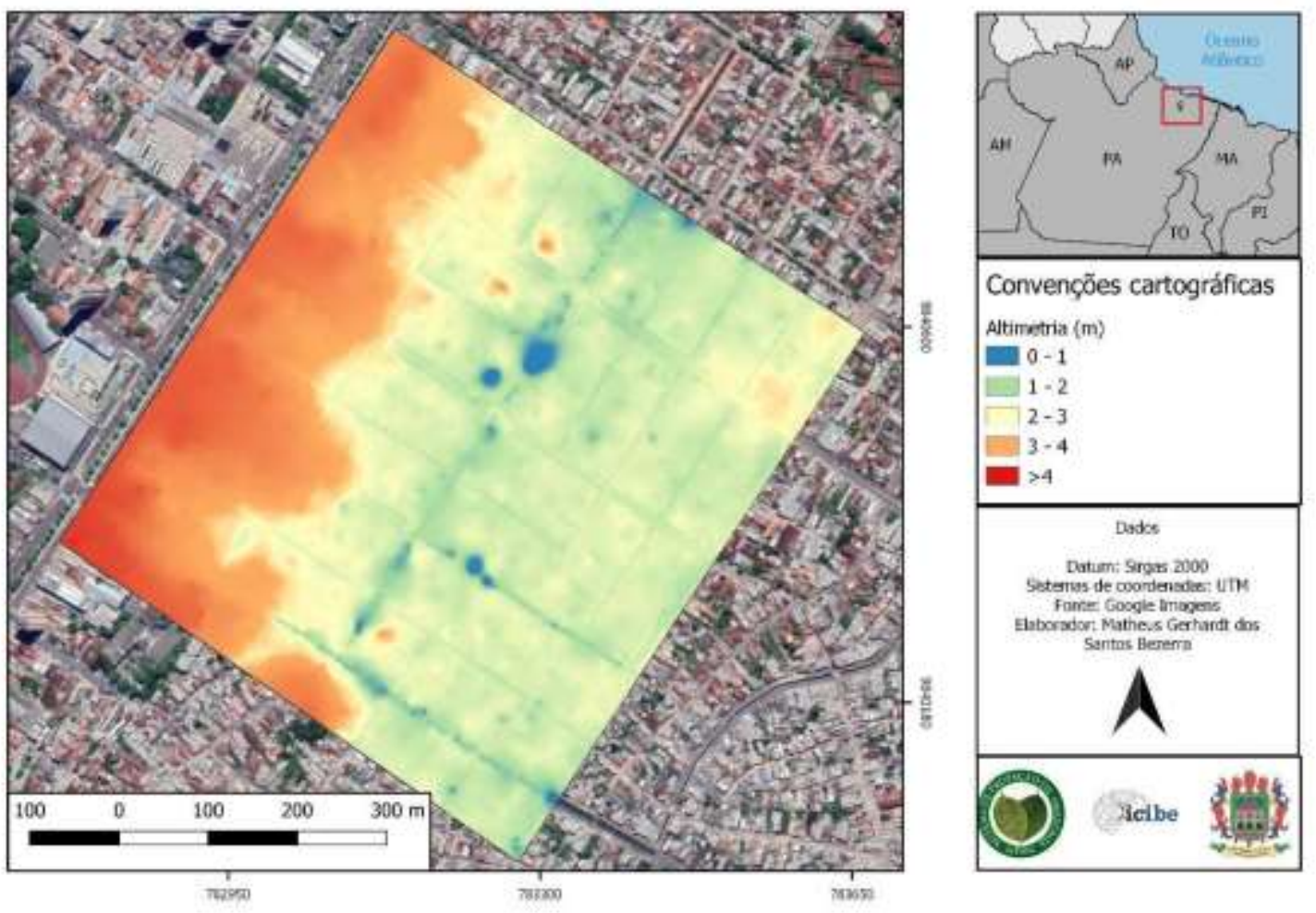

Fonte: Bezerra (2019).

No bairro é perceptível uma redução de cota topográfica a partir da Avenida João Paulo II. Bezerra (2019) comprova esse fato altimétrico a partir de aerolevantamentos, onde a mencionada avenida encontra-se em cotas superiores à $3 \mathrm{~m}$ e as ruas ao leste de $3 \mathrm{~m}$ a $0 \mathrm{~m}$.

\section{Referencial Bibliográfico}

\subsection{Localização e caracterização da área de estudo}

A capital paraense, Belém está localizada na região do delta do Rio Amazonas, na foz do Rio Guamá com a Baía do Guajará. De acordo com Costa (2001) a geologia regional é dividida em três perfis litológicos: sedimentos recentes, sedimentos Barreiras/Pós Barreiras e formação de Pirabas. Por possuir um perfil litológico sedimentar há o domínio de solos argilosos e siltosos na região. Ainda mais, lista-se as três argilas e o silte mais frequente na região, descritas por Alencar Jr, Fraiha Neto, Saré e Mendonça (2002) e Farias e Cardoso (2001) e citadas por Salame (2003).

- Argila orgânica muito mole (SPT realizados indicam entre 0 e 1);

- Argila variegada mole à média (SPT médios de 4 e 5);

- Argila mole à média cinza escura (SPT médios de 4 a 6);

- Silte arenoso variegado fofo a pouco compactado (SPT médios de 1 a 6).

\subsection{Investigação geotécnica}

Queiroz (2016) retrata a importância do estudo do subsolo para a realização de um dimensionamento estrutural seguro e com previsão do comportamento que o solo apresentara na construção de uma edificação. Falconi et al. (1998) ratifica que estes estudos são realizados predominantemente através de ensaios em campo. De acordo com Schnaid e Odebrecht (2012), a 
complexidade da obra, fatores de segurança, riscos e caraterísticas do meio físico são parâmetros para a definição do método de exploração do subsolo. Existem vários métodos para tal estudo, os de caráter não destrutivos ou semi destrutivos, não invasivos e combinados (Schnaid, 2009).

No entanto, a investigação preferencial é do Standard Penetration Test (SPT), um ensaio invasivo que, de acordo com Salame (2003), tem sua primazia por ser direto e de baixo custo. Dá-se através de coletas amostrais para definição das propriedades do solo como nível do lençol freático e obtenção do índice de resistência a penetração (NSPT). Através deste índice calculam-se fundações rasas bem como as profundas, assim como a classificação de argilas e areias. Para que se tenha resultados confiáveis é necessário que o ensaio seja fundamentado pela NBR 6484 (2001).

Salomão e Jahel (2019), ao analisar uma obra fictícia com e sem estudo do solo, encontraram 21,49\% de economia de concreto quando as sondagens são realizadas. Portanto, a falta de acesso a métodos de investigação do subsolo encarece significativamente as obras.

Bitar, Freitas e Macedo (2015) destacam a importância do mapeamento geotécnico, o qual pode ser realizado em campo e laboratório, como uma ferramenta que possibilita conhecer o meio geológico em qual irá ocorrer a ocupação do solo e consequentemente uma intervenção estrutural, para que sejam realizadas de forma adequada e segura. $\mathrm{O}$ estudo integra dados e informações básicas sobre as características geotécnicas dos terrenos em uma determinada área.

Oliveira (2014) assegura que é indispensável o conhecimento das características do solo e dos consequentes impactos em virtude das ações antrópicas nas modificações do ambiente, sendo assim, definindo áreas de ocupações aceitáveis, seguras e com baixo impacto ao ambiente.

\subsection{Geoestatística}

A Geoestatística tem por objetivo a caracterização espacial de uma variável de interesse por meio do estudo de sua distribuição e variabilidade espaciais, com determinação das incertezas associadas.

\subsubsection{Variáveis Regionalizadas (VR)}

A teoria das variáveis regionalizadas, Segundo Matheron (1963, citado por Alves, 2016, 24) sugere modelar fenômenos que possuam alguma distribuição no espaço com variáveis que dependem de um valor e de uma posição espacial. Em trabalhos de geoestatística opta-se por um modelo que é baseado em funções aleatórias, a qual indica que cada ponto no espaço é representado por uma variável aleatória, sendo assim, obtendo-se um conjunto de variáveis que formam um vetor aleatório com dimensão infinita e não-enumerável, ou seja, uma função aleatória.

\subsubsection{Semivariograma}

Por sua vez, é uma função de incremento com a distância h, uma vez que, a distância geoespacial entre as amostras é inversamente proporcional aos seus valores em média. Esta característica retrata a respeito da zona de influência de cada ponto de observação (Sturaro, 2015).

Bragança (2021) indica que a variabilidade espacial é identificada a partir da estimação do semivariograma e construção do gráfico, o que permite a representação da semivariância em função da distância.

A interpolação de valores para criação de mapas a partir de propriedades específicas pode ser realizada por diversos algoritmos geoestatísticos como a krigagem e a simulação sequencial gaussiana. Esta última é utilizada como alternativa a krigagem, a fim de eliminar o efeito de suavização existente no método (Teixeira et al., 2011). No entanto, esta suavização não está isenta de erros na criação dos mapas geotécnicos, podendo-se afirmar que, em média, as imprecisões são maiores que da krigagem (Yamamoto, 2017). 


\section{Metodologia}

Este capítulo apresenta os métodos desta pesquisa, cuja abordagem é quantitativa e segue as metodologias de Cruz (2017), Alves (2016) e Pereira et al. (2018).

\subsection{Catalogação do Banco de Dados}

Para esta pesquisa foram utilizados 101 boletins de sondagem SPT cedidos por duas empresas especializadas em sondagens do tipo SPT e reconhecidas no mercado local. De cada um foram extraídas as informações de tipo de solo e profundidade das camadas, nível do lençol freático e índice de resistência à penetração (NSPT), conforme normatiza a NBR 6484/2001. As informações foram cuidadosamente organizadas em um banco de dados que permitisse melhor análise, interpretação e exportação destas. A área de estudo está localizada em uma região onde é comum a ocorrência de aterros, portanto as camadas contendo tal descrição foram desconsideradas. Adotou-se o valor de 50 golpes como limite para o NSPT.

Os detalhes informados no croqui de localização e endereço contido nos boletins viabilizaram a geolocalização dos furos de sondagem. Cada coordenada, em UTM (Universal Transversa de Mercator), compôs o banco de dados, dado que os perfis estão intimamente vinculados à sua posição espacial.

\subsection{Mapeamento do Índice de Resistência a Penetração}

\subsubsection{Estatística}

Para facilitar a visualização dos dados amostrais, a estatística descritiva foi aplicada através das medidas de locação (ou centralidade) e dispersão. Elas permitem um entendimento prévio do conjunto em poucas análises, porém sem relação espacial.

\subsubsection{Geoestatística}

O software SGeMS é livre e de código aberto, com visual simplificado e de fácil utilização. Nele é possível a realização de diversas análises estatísticas e geoestatísticas, tanto de estimação quanto de simulação. Através desse foi elaborado um pacote de análises em duas dimensões (2D) para cada profundidade de camada (3, 5 e 10 metros). Cada pacote contém:

- Histograma;

- Variograma;

- Simulação Sequencial Gaussiana.

\subsubsection{Geoprocessamento}

Utilizou-se o software Qgis 3.14, um software Open Source, para realizar as análises em SIG (Sistema de Informação Geográfica) e layout dos mapas.

\section{Resultados e Discussão (pode ser separado ou junto) (fonte TNR 12 - alinhado esquerda)}

\subsection{Estatística descritiva}

A Tabela 1 indica os parâmetros estatísticos das profundidades estudadas. 
Tabela 1: Parâmetros estatísticos (tendência central e dispersão) dos valores de NSPT às profundidades de 3,5 e 10 m.

\begin{tabular}{c|c|c|c}
\hline Estatística & $3 \mathrm{~m}$ & $5 \mathrm{~m}$ & $10 \mathrm{~m}$ \\
\hline Média & 8,95 & 16,75 & 25,63 \\
Erro padrão & 0,92 & 1,44 & 2,31 \\
Mediana & 7 & 15 & 36 \\
Moda & 0 & 0 & 0 \\
Variância & 83,01 & 206,04 & 335,07 \\
Coef. De variação & $98 \%$ & $117 \%$ & $140 \%$ \\
Assimetria & 0,98 & 1,17 & 1,4 \\
Amplitude & 42 & 48 & 48 \\
No de amostras & 99 & 99 & 63 \\
\hline
\end{tabular}

Fonte: Autores.

A partir da análise da Tabela 1 observa-se que as medidas de dispersão apresentam altos valores, que indicam a discrepância das medidas de tendência central. A forte assimetria mostra que valores extremos tendem a aumentar a média aritmética ao ponto de torná-la inexpressiva. Esse fato também é identificado pela elevada amplitude entre as amostras.

Os dados de entrada estão contidos em uma área grande, o que torna a estatística clássica insuficiente para descrever com clareza as características geotécnicas da região. Para obtenção de valores representativos lança-se mão da geoestatística, a fim de regionalizar as variáveis para simulação de valores mais realísticos.

\subsection{Profundidade 3 metros}

Na primeira profundidade, 3 metros, foram utilizadas 99 amostras válidas, das quais $15 \%$ apresentam NSPT=0 e pouco mais de $17 \%$ requereram mais de 15 golpes neste atributo. Quanto às medidas de dispersão, o histograma apresenta padrão moderadamente assimétrico, positivo e coeficiente de variação em 98\%. Estes dados indicam que as amostras possuem forte dispersão. A variância é de 83,01 (Figura 2a).

Para os parâmetros de entrada dos variogramas omnidirecionais deste estudo foram atribuídos número, tamanho e tolerância de classes, respectivamente em 55, 30 e 5, com angulações nulas, tolerância angular e limite de direção em 90. 
Figura 2: a) Histograma dos valores de NSPT medidos à $5 \mathrm{~m}$ de profundidade; b) variograma omnidirecional de NSPT medidos à $5 \mathrm{~m}$ de profundidade.
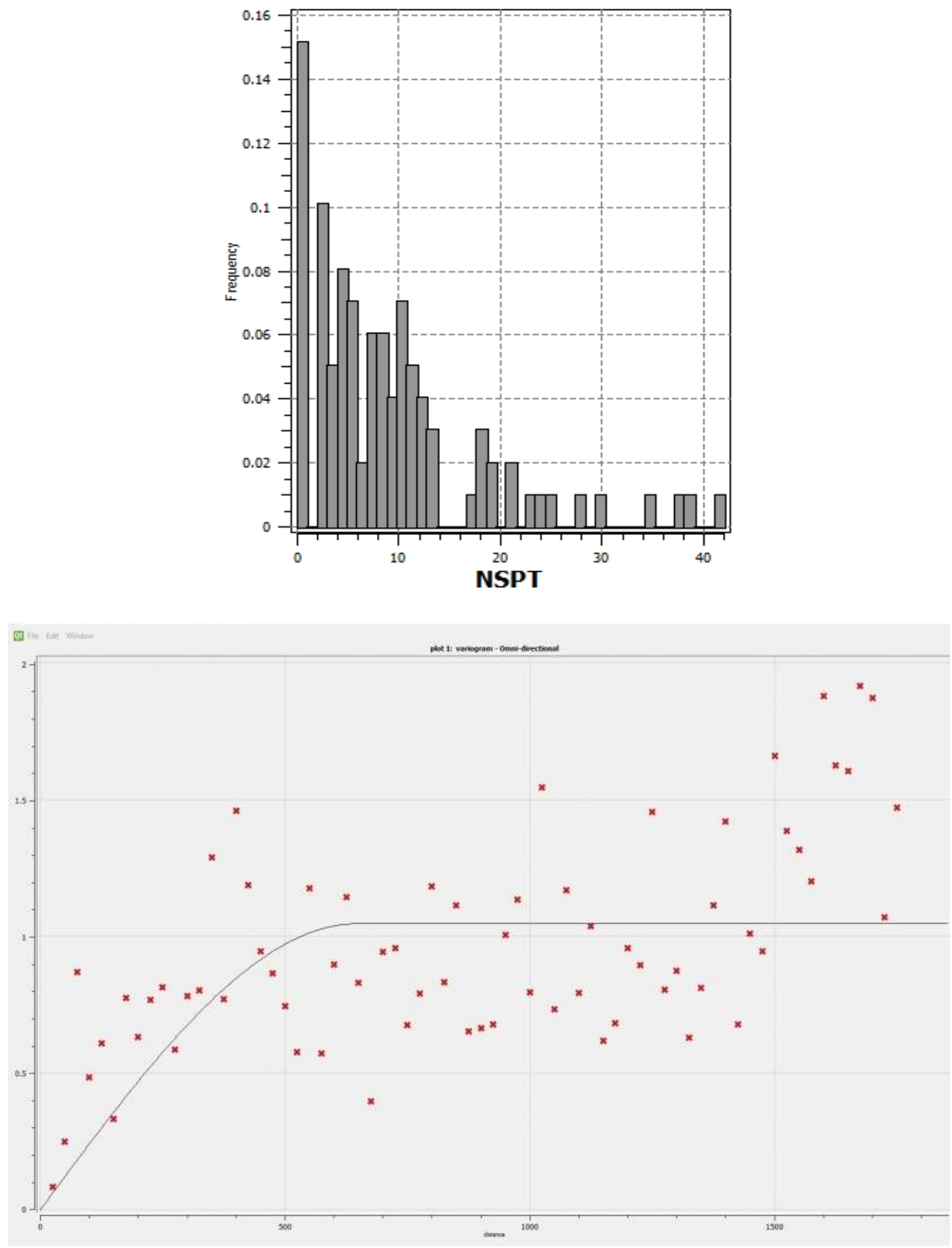

Fonte: Autores.

O variograma que melhor representou foi ajustado no formato esférico, com patamar 83.01, sem efeito pepita e alcances de 700, 250 e 100 (Figura 2b).

Com os dados de entrada, a simulação com uma realização gerou a imagem no QGIS, foi utilizada na representação da Figura 3. 
Research, Society and Development, v. 10, n. 2, e40810212664, 2021

(CC BY 4.0) | ISSN 2525-3409 | DOI: http://dx.doi.org/10.33448/rsd-v10i2.12664

Figura 3: Mapa de distribuição dos valores de NSPT à $3 \mathrm{~m}$ de profundidade.

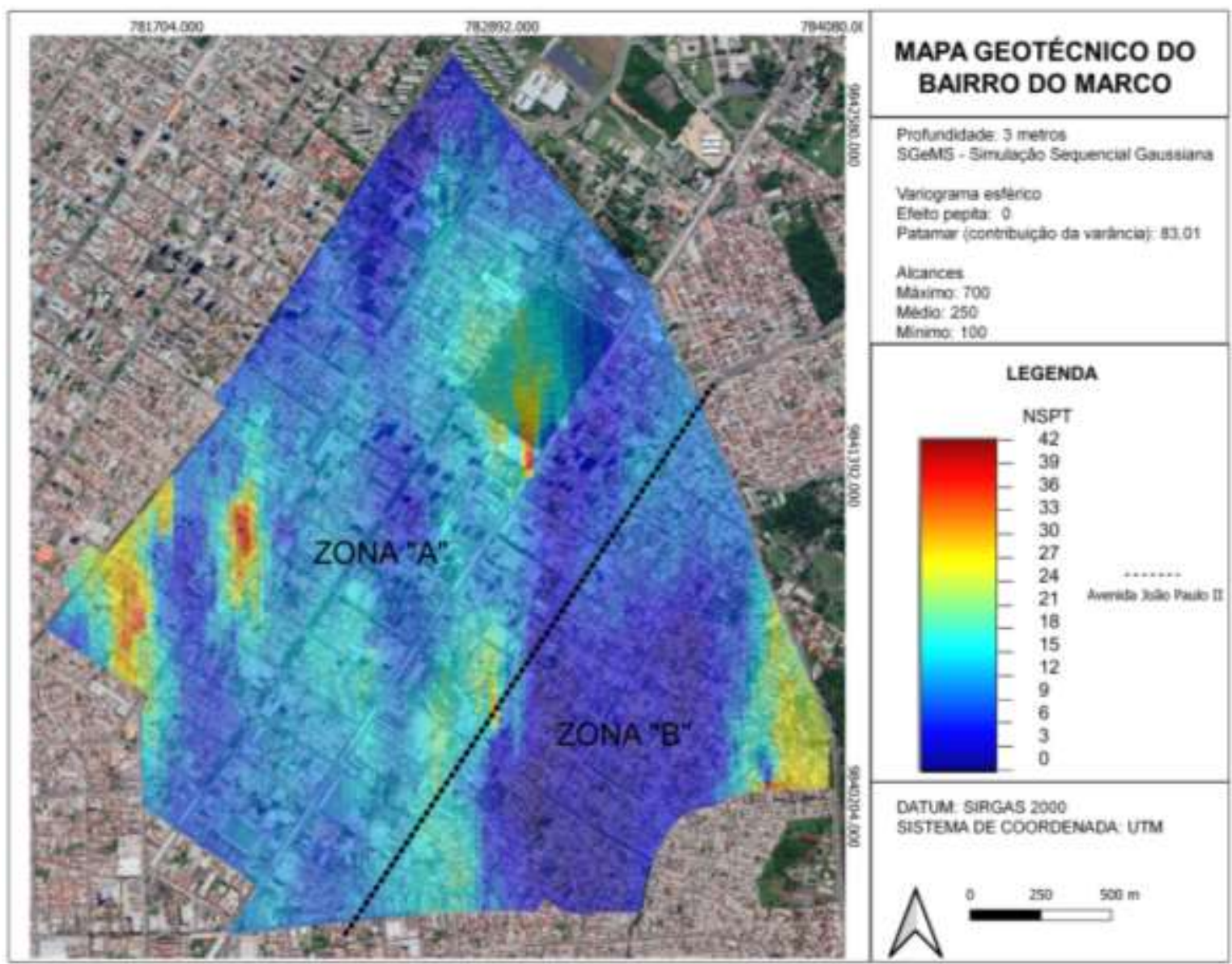

Fonte: Autores.

Na Figura 3 nota-se uma grande mancha (com cor azul) de baixa resistência (NSPT<10) presente no centro da zona B, com a existência de lentes pouco mais resistentes no extremo leste (NSPT>20). Na zona A ocorre o aumento do índice em relação à região oposta, que variou entre 0 a 18 golpes, possuindo também algumas regiões com resistência satisfatória para fundações profundas, com NSPT entre 27 e 42.

\subsection{Profundidade 5 metros}

Na segunda camada analisada, 5 metros, conforme ilustrado na Figura 4, analisou-se 99 amostras, e 17\% apresentam índice de resistência à penetração nulo e $23 \%$ igual ou superior a 30 golpes. Em relação à dispersão, o histograma é altamente assimétrico, positivo, com coeficiente de variação em 117\% e variância de 206,04 (Figura 4a). 
Figura 4: a) Histograma dos valores de NSPT medidos à $5 \mathrm{~m}$ de profundidade; b) variograma omnidirecional de NSPT medidos à $5 \mathrm{~m}$ de profundidade.
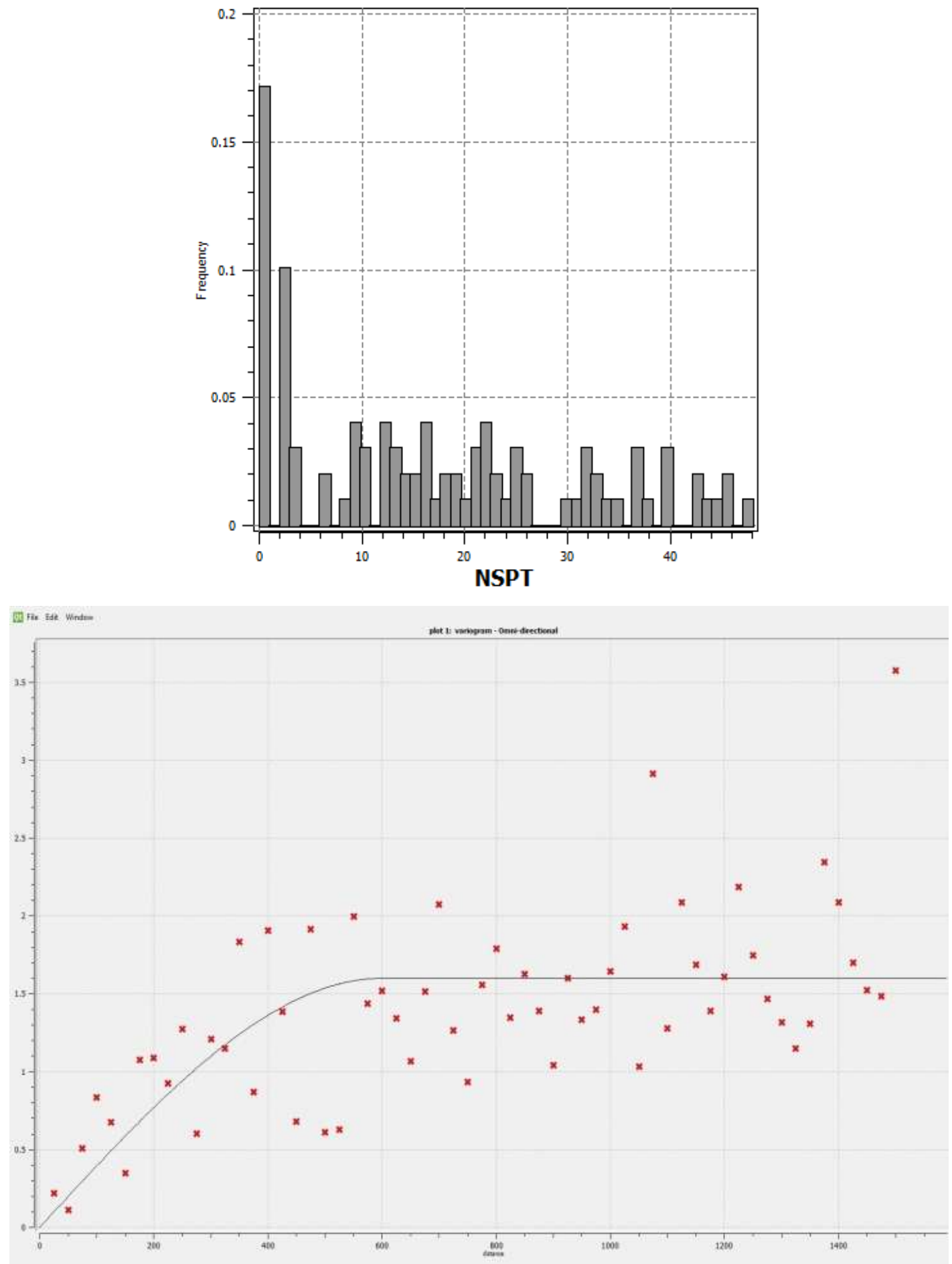

Fonte: Autores.

O variograma tem ajuste para o formato esférico, com patamar 206.04, sem efeito pepita e alcances de 600, 200 e 100 (Figura 4b).

A simulação utilizando a configuração do variograma expresso na Figura 4 gerou a imagem que, após ajustes cartográficos no QGIS, foi utilizada na representação da Figura 5. 
Research, Society and Development, v. 10, n. 2, e40810212664, 2021

(CC BY 4.0) | ISSN 2525-3409 | DOI: http://dx.doi.org/10.33448/rsd-v10i2.12664

Figura 5: Mapa de distribuição dos valores de NSPT à $5 \mathrm{~m}$ de profundidade.

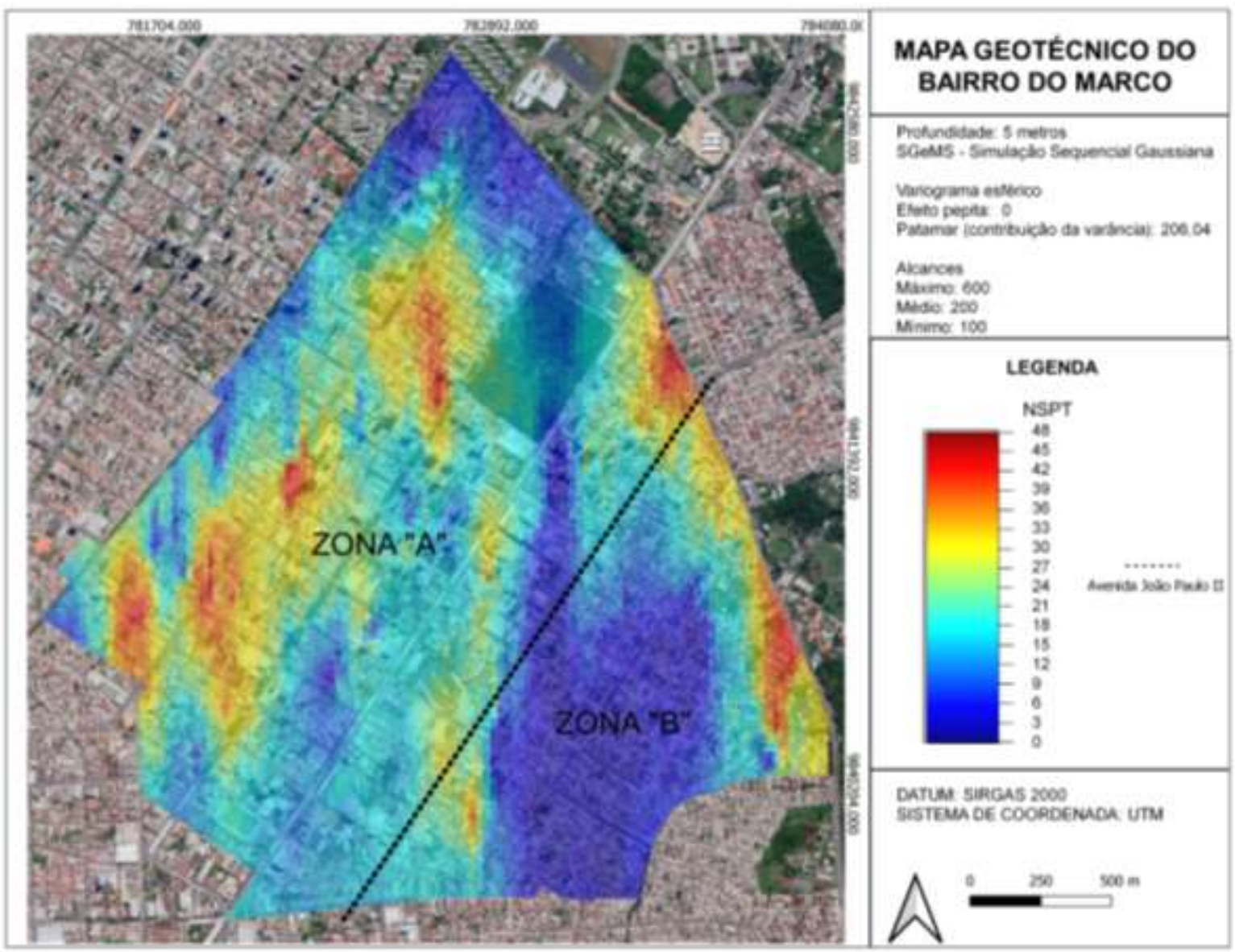

Fonte: Autores.

Nessa camada há a expansão das manchas que indicam resistência entre 27 e 46 golpes na zona A, porém com queda deste índice conforme a aproximação com a zona oposta. Ainda mais, a partir da observação do mapa, identifica-se que na zona B existe a redução da área de baixa resistência observada na profundidade anterior, com elevação dos valores ao leste, alcançando entre 27 a 42 golpes.

\subsection{Profundidade 10 metros}

O nível de 10 metros há redução da nulidade dos índices, aproximando-se dos $20 \%$ das amostras, e ampliação dos dados superiores a 30 golpes $-52 \% .63$ amostras foram validadas, posto que as demais 38 sondagens finalizaram-se em cotas inferiores à profundidade de 10 metros. O histograma apresenta-se com forte assimetria, positivo, 140\% de coeficiente de variação, e variância de 335,07, conforme Figura 6a. 
Figura 6: a) Histograma dos valores de NSPT medidos à $10 \mathrm{~m}$ de profundidade; b) variograma omnidirecional de NSPT medidos à $10 \mathrm{~m}$ de profundidade.
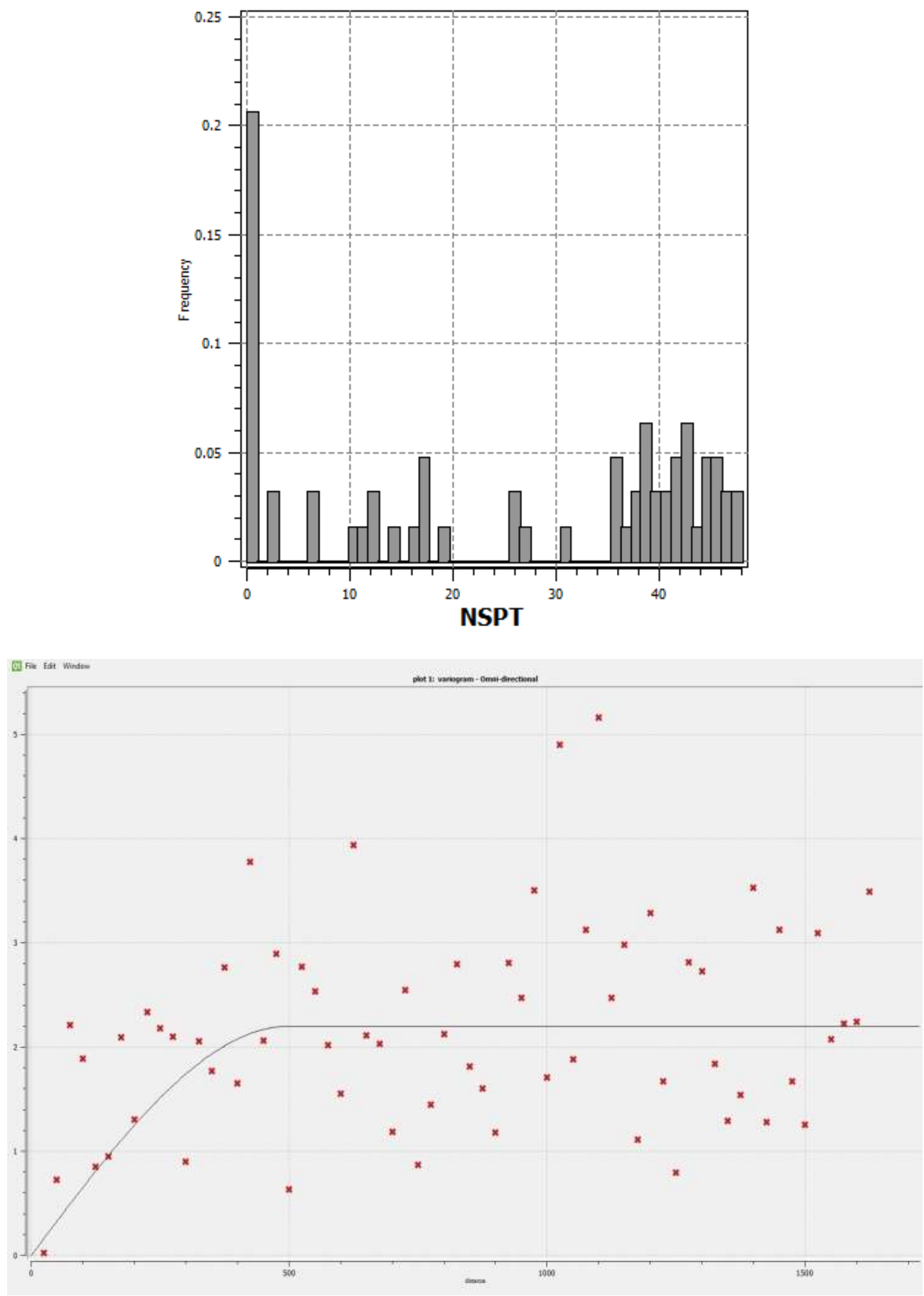

Fonte: Autores.

O variograma ajustado no modelo esférico, com patamar 335,07 e alcances de 500, 250 e 200 (Figura 6b).

A simulação utilizando a configuração do variograma da figura 6 b gerou a imagem representação da Figura 7. 
Research, Society and Development, v. 10, n. 2, e40810212664, 2021

(CC BY 4.0) | ISSN 2525-3409 | DOI: http://dx.doi.org/10.33448/rsd-v10i2.12664

Figura 7: Mapa de distribuição dos valores de NSPT à $10 \mathrm{~m}$ de profundidade.

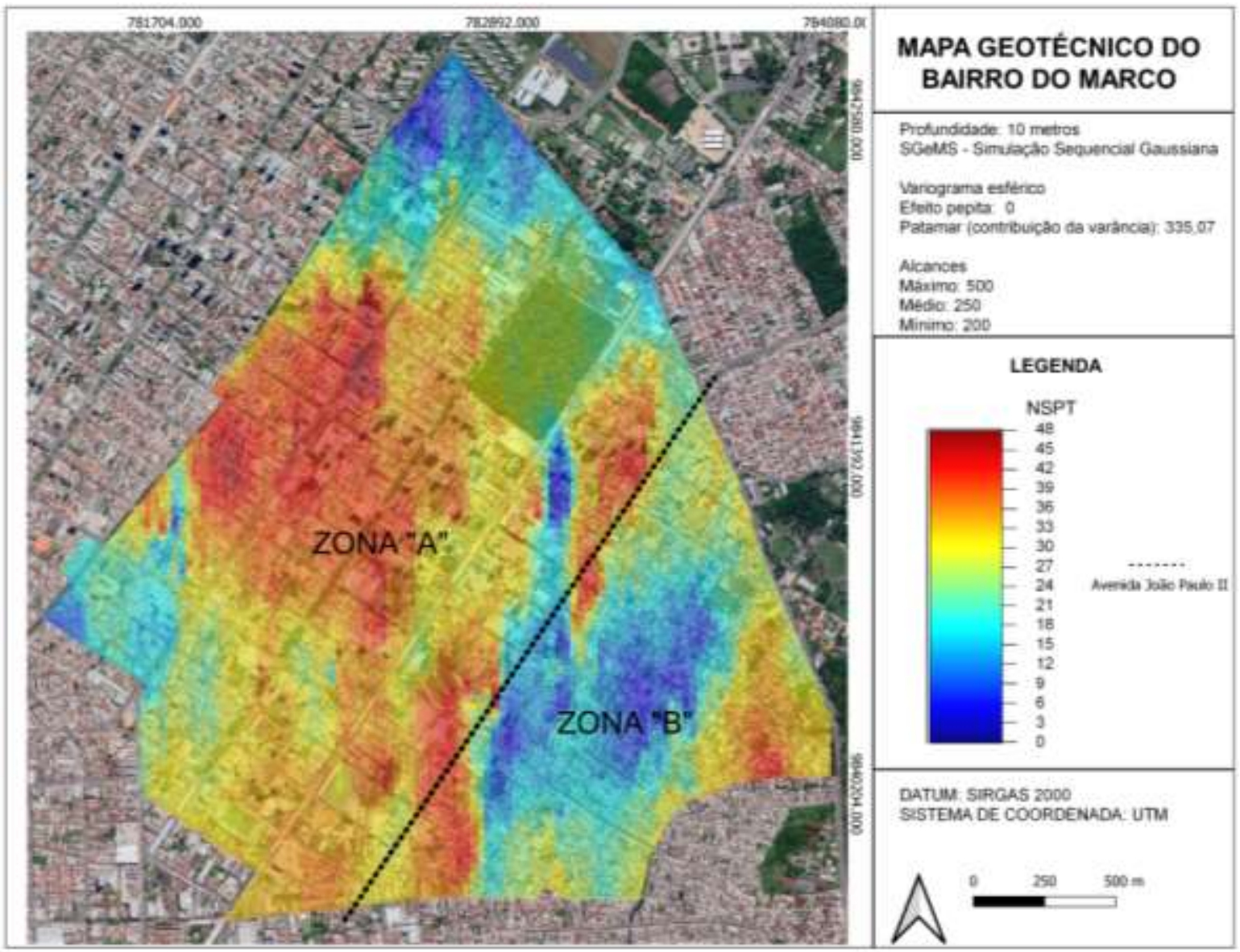

Fonte: Autores.

Finalmente, foi possível identificar que na profundidade de 10 metros (Figura 7) há regiões com valores altos de NSPT. Portanto, pode-se afirmar que, na maior parte da área de estudo, o índice de resistência à penetração assume valores superiores a 25 golpes. Entretanto, estas características são opostas à área central da zona B (Figura 7), onde há a permanência de baixos índices de resistência, que podem ser justificados pela presença de diversos canais a céu aberto, com indícios de zonas de várzea, indicados na Figura 8. 
Research, Society and Development, v. 10, n. 2, e40810212664, 2021

(CC BY 4.0) | ISSN 2525-3409 | DOI: http://dx.doi.org/10.33448/rsd-v10i2.12664

Figura 8: Localização dos canais à céu aberto.

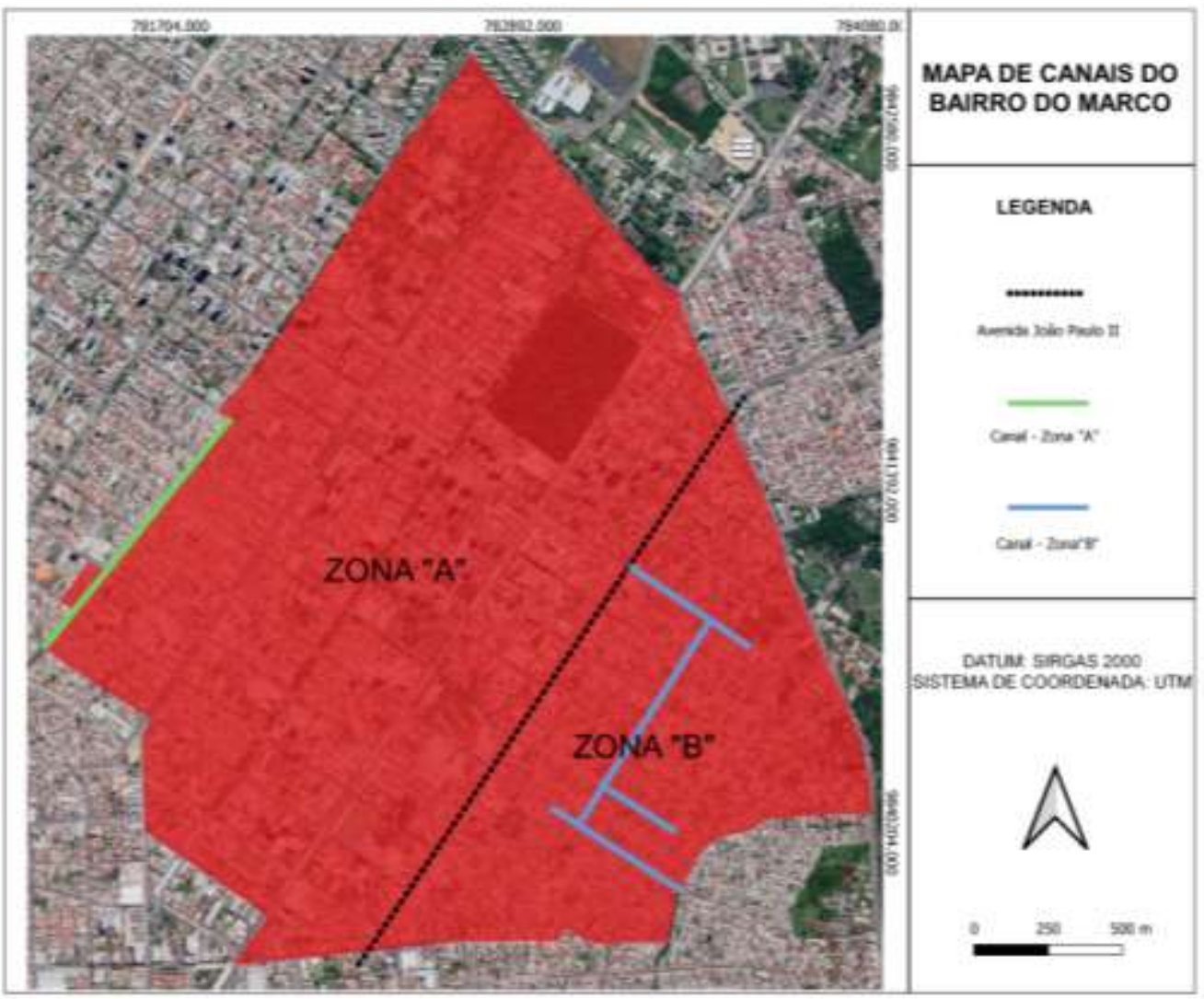

Fonte: Autores.

A Figura 8 delimita o bairro do Marco, em vermelho. A área de estudo é segmentada em zonas "A" e "B" a partir da Avenida João Paulo segundo, indicada pela linha tracejada preta. Os canais à céu aberto são indicados em verde (zona “A”) e azul (zona “B”). As disparidades podem ser vistas, inclusive, de imagens aéreas, como mostra a Figura 9.

Figura 9: Subdivisão da área estudada em zonas “A” e "B” por vista aérea.

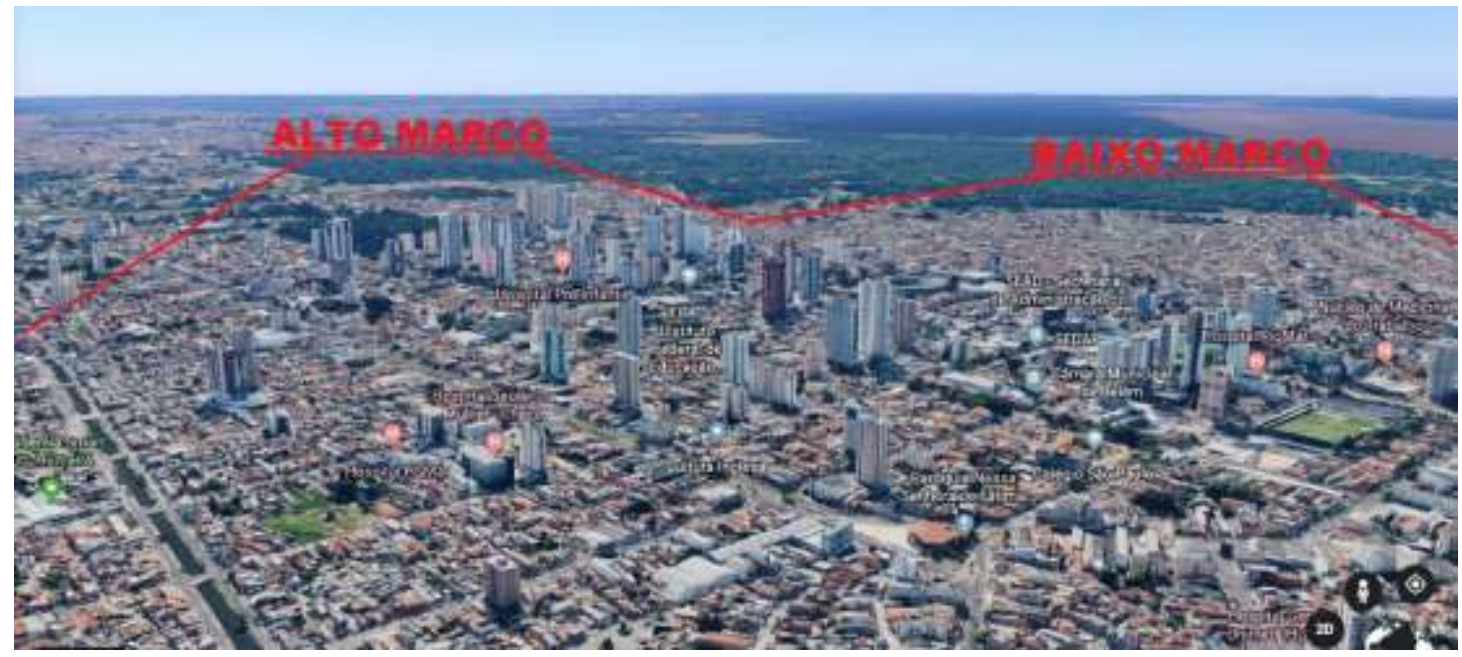

Fonte: Autores. 
Uma é a área nobre (zona A), com alta concentração de edificações de grande porte, menor ocorrência de alagamentos, melhor escoamento viário para os demais bairros da metrópole, além de melhor infraestrutura urbana. Na periferia (zona B), são encontrados cinco canais a céu aberto, residências unifamiliares de pequeno porte, maior incidência de patologias relativas ao recalque diferencial e maior vulnerabilidade a alagamentos.

Salame (2003), ao analisar a relação do perfil geotécnico com as fundações usuais de Belém, indica que aproximadamente $93 \%$ das fundações praticadas em perfis de várzea são estacas, enquanto sapatas e tubulões representam $82 \%$ das fundações nos perfis similares à zona A. Belém é uma metrópole onde, atualmente, ocorre o crescimento para bairros mais distantes. Apesar do bairro do Marco estar localizado a poucos minutos do centro, em pouco é notado o progresso da zona periférica, uma vez que o alto custo para soluções geotécnicas e urbanas na região afasta possíveis investidores.

\section{Conclusão}

O contexto histórico da expansão de Belém corroborou para que as várzeas fossem urbanizadas de forma irregular ao ponto de gerar resquícios que perduram por gerações. A qualidade de vida dos moradores dessas áreas é afetada, já que sofrem com os frequentes alagamentos e pouca infraestrutura urbana. A desigualdade entre as zonas A e B é vista há décadas, desde a forma desordenada que ocorreram as primeiras ocupações das várzeas até o evidente contraste entre altos prédio e casas recalcadas. A necessidade de mais áreas urbanas continentaliza a Metrópole cada vez mais, descartando a reestruturação da periferia do Marco. Esta pesquisa possibilitou a visualização do impacto que a geotecnia causa na urbanização de uma das cidades mais importantes da Amazônia.

A geoestatística descreve os dados amostrais com maior clareza que a estatística descritiva. As imagens resultantes da simulação são capazes de inferir, com menor suavização global, dados desconhecidos a partir da teoria de variáveis regionalizadas.

Os resultados indicam que a zona A apresenta resistência satisfatória em níveis superficiais. Em contrapartida, a zona oposta (Zona B) permanece com baixos índices de resistência à penetração até a cota limite da pesquisa, 10m. Autores referência na região descrevem argilas orgânicas de baixa resistência nas proximidades das áreas de várzea onde, atualmente, os igarapés foram retificados e localizam-se as regiões de baixa resistência descritas nos resultados dessa pesquisa.

Os custos de soluções geotécnicas em várzeas belenenses tornam-se questionáveis quando propostos para um cenário de baixa infraestrutura urbana. São necessários investimentos governamentais em obras urbanas da região para que, finalmente, haja a melhoria da qualidade de vida dos moradores da várzea periférica e maior custo-benefício para a construção civil.

Para pesquisas futuras sugere-se a confirmação dos mapas simulados com sondagens reais, bem como ampliação do banco de dados para pesquisas maiores.

\section{Referências}

ABNT, N. (2001). 6484. Solo - Sondagens de simples reconhecimento com SPT-Método de Ensaio. Associação Brasileira de Normas Técnicas, Rio de Janeiro.

Alves, C. N. (2016). Modelagem geológica e geomecânica tridimensional dos sedimentos subterrâneos da região de Ipanema e Leblon, Rio de Janeiro.

Bezerra, M. G. D. S. (2019). Análise quantitativa da vulnerabilidade a inundação a partir de aerolevantamentos com VANTS Multirotores no bairro do Marco, Belém-PA. 63 f. Monografia (Trabalho de Conclusão de Curso), Universidade Federal Rural da Amazônia, Belém.

Bitar, O. Y., Freitas, C., \& Macedo, E. (2015). Guia Cartas geotécnicas: orientações básicas para os municípios. São Paulo: IPT - Instituto de Pesquisas Tecnológicas do Estado de São Paulo.

Bragança, R. G. Bayesian inference applied to linear regression model and spatial model: An approach on the covariance structure between geostatistical data. Research, Society and Development, 10(1), e31910111890, 2021. 10.33448/rsd-v10i1.11890.

Costa, T. C. D. D. (2001). Análise crítica das metodologias gerais de mapeamento geotécnico visando formulação de diretrizes para a cartografia geotécnica no trópico úmido e aplicação naregião metropolitana de Belém escala 1:50.000. 256 f. Tese (Doutorado em Geologia e Geoquímica), Universidade Federal 
Research, Society and Development, v. 10, n. 2, e40810212664, 2021

(CC BY 4.0) | ISSN 2525-3409 | DOI: http://dx.doi.org/10.33448/rsd-v10i2.12664

do Pará, Belém.

Cruz, G. A. D. (2017). Modelagem geológica tridimensional de argilas no software SGeMS, segundo perfis de sondagem à percussão no bairro Jardim Botânico (RJ). 83 f. Monografia (Trabalho de Conclusão de Curso), Universidade Federal do Rio de Janeiro, Rio de Janeiro.

Falconi, F. F., Corrêa, C. N., Orlando, C., Schimdt, C., Antunes, W. R., Albuquerque, P. J., \& Niyama, S. (1998). Fundações: teoria e prática. Oficina de textos.

Matos, F. (2010). Caracterização qualitativa dos impactos ambientais causados pela ocupação urbana no Igarapé do Tucunduba, Belém, PA. 122 f. Dissertação (Mestrado em Ciências Ambientais), Universidade de Taubaté, São Paulo.

Moreira, E. (1966). Belém e sua expressão geográfica. Belém: Imprensa Universitária/UFPA (1ª ed.).

Oliveira, F. P. D. (2014). Mapeamento geotécnico preliminar e aplicação do Modelo SHALSTAB na análise de escorregamentos da bacia de Santo Antônio de Lisboa-Florianópolis/SC. 198 f. Monografia (Trabalho de Conclusão de Curso), Universidade Federal de Santa Catarina, Florianópolis.

Penteado, A. R. (1968). Belém: estudo de geografia urbana. http://livroaberto.ufpa.br/jspui/handle/prefix/43

Pereira A.S. et al. (2018). Metodologia da pesquisa científica. UFSM.

Queiroz, R. C. (2018). Geologia e geotecnia básica para engenharia civil. Editora Blucher.

Salame, A. (2003). Mapeamento das Fundações Mais Usadas na Cidade de Belém-PA, Aspectos gerais e Proposta preliminar de mapeamento de soluções utilizadas em casos recentes. Dissertação (Mestrado), Universidade Federal do Pará, Belém.

Salomão, P. E. A.; \& Jahel, R. S. Impact of solo surfacing on the value of the project. Research, Society and Development, 8(12), e038121367. 10.33448/rsdv8i12.1367.

Schnaid, F. (2009). In Situ: Testing in Geomechanics. 1. 329. Oxon.

Sturaro, J. R. (2015). Apostila de geoestatística básica. UNESP.

Targa, M. D. S., Batista, G. T., Diniz, H. N., Dias, N. W., \& Matos, F. C. D. (2012). Urbanização e escoamento superficial na bacia hidrográfica do Igarapé Tucunduba, Belém, PA, Brasil. Revista Ambiente \& Água, 7(2), 120-142.

Teixeira, D. D. B., Panosso, A. R., Perillo, L. I., Iamaguti, J. L., Pereira, G. T., \& Júnior, N. L. S. (2011). Krigagem ordinária e simulação sequencial gaussiana na interpolação da emissão de CO2 do solo. Energia na Agricultura, 26(3), 26-42.

Vieira, M. N. A \& Cruz, R. R. (2019). Mapeamento geotécnico com software SGeMS a partir de perfis de sondagem à percussão no bairro do Marco, em Belém do Pará. Monografia (Trabalho de Conclusão de Curso), Centro Universitário Metropolitano da Amazônia, Belém.

Yamamoto, J. K. (2017). Geokrigagem: Geoestatística - Simulação Sequencial Gaussiana. https://geokrigagem.com.br/simulacao-gaussiana-sequencial/. 